\title{
Vibrio vulnificus Infection in São Paulo, Brazil: Case Report and Literature Review
}

\author{
Maria Rita Elmor de Araujoㅇ, Caroline Aquino ${ }^{1}$, Elton Scaramal ${ }^{2}$, Claudete Sílvia Ciola ${ }^{1}$, \\ Guilherme Schettino ${ }^{2}$ and Marcel Cerqueira Cesar Machado ${ }^{3}$ \\ ${ }^{1}$ Clinical Microbiology Laboratory, ${ }^{2}$ Intensive Care Unit, ${ }^{3}$ Clinic Staff; Sírio Libanês Hospital; São Paulo, SP, Brazil
}

\begin{abstract}
Non cholera Vibrio may cause conjunctivitis, wound infection, gastroenteritis and serious sepsis. Transmission to men is through contact with skin, mucosa or wounds exposed to marine water, and consumption of certain barely cooked or raw seafood, more frequently in the summer. This is one of the first cases of severe infection related to Vibrio vulnificus described in Brazil. The patient was an old man, who ingested seafood in Guarujá, a seashore city near São Paulo, 3 days before hospitalization. He was admitted to the emergency room in an ill state with septic shock. On 2 sets of blood culture a highly virulent microorganism was isolated, Vibrio vulnificus, which leads to sepsis and frequently to death in susceptible patients. The objective of this report was to use this case to discuss clinical aspects, microbiological diagnosis and treatment of the infection caused by this agent, besides the review of epidemiology, associated risk factors and prevention before consuming or getting in contact with seafood, especially in patients with greater susceptibility to this kind of infection.
\end{abstract}

Key-Words: Vibrio vulnificus, septic shock, risk factors.

Male, 86 years old, living in São Paulo, was attended at the emergency room of Hospital Sirio Libanês (São Paulo, SP, Brazil), on January $3^{\text {rd }} 2004$ with a history of 3 days. After having ingested seafood (mussels and octopus) in Guarujá (SP), he began to present vomiting and diarrhea, reduction of liquid intake, poor diuresis, and fever of $39^{\circ} \mathrm{C}$ at the day of admission. Other 5 relatives, who ingested the same meal, did not show symptoms at anytime.

Medical history. In 1999, he was submitted to a gastroduodenopancreatectomy because of a chronic pancreatitis. Hepatic steatosis with hepatomegaly (ultrasonography), non dialytic chronic renal failure and systemic arterial hypertension are other diseases already presented by the patient. Social drinker.

Physical examination. Dehydration $4+/ 4$, cyanosis $4+/ 4$, cutaneous paleness.

Respiratory. Presence of bilateral murmur, RF: 35/min, $\mathrm{O}_{2}$ Saturation: $88 \%$ in ambient air and $94 \%$ with $\mathrm{O}_{2}$ mask.

Cardiac. Regular rhythm with normal sounds, thin pulse at 84/ min, blood pressure $=70 / 40 \mathrm{mmHg}$.

Abdominal. Flaccid, tympanic at percussion, diminished bowel sounds.

Neurological. Conscious, oriented, agitated, without motor impairment, with isochoric and photo reagent pupils.

Inferior members. Presence of hyperemia on the right ankle.

Received on 15 August 2006; revised 9 December 2006.

Address for correspondence: Dr. Maria Rita Elmor de Araújo. Rua Gustavo Teixeira, 366 - ap 16. Zip code: 01236-010 - Pacaembu - São Paulo SP, Brazil.

The Brazilian Journal of Infectious Diseases

2007;11(2):302-305. (C) 2007 by The Brazilian Journal of Infectious Diseases and Contexto Publishing. All rights reserved.
Blood cultures, hemogram and other laboratory examinations had been harvested.The hemogram of entrance presented leucocytosis with important left shift.

Soon after the admission, he evolved with septic shock, respiratory failure needing mechanic ventilation and hypotension not responsive to volume replacement, needing vasoactive drugs in high doses.

The right inferior member evolved quickly with violaceous blisters, which later presented necrosis (Figure), being indicated surgical debridement. Initially, it was instituted empirical antibiotic therapy with metronidazole and ampicillin. Blood cultures were positive after 9 hours of incubation. The Gram stain disclosed Gram-negative bacilli, and the sample was then plated on MacConkey, sheep blood and chocolate agar. After 6 hours, there was already bacterial growth when the positive oxidase test was verified, and it was suggested that it could be from genus Pseudomonas. The intensive care unit (ICU) was informed immediately, being then indicated the addition of cefepime. After 24 hours of incubation, bacteria presented mucoid aspect and yellow-greenish colored colonies on blood and chocolate agar, however it did not have growth on MacConkey agar. The biochemical identification was carried out on the automated system VITEK (bioMerieux ${ }^{\circledR}$ ) and indicated Vibrio vulnificus. Although the Gram stain of the wound secretion from inferior member evidenced the presence of Gram-negative bacilli, the culture was negative (the collection was done after the beginning of antibiotic therapy).

The susceptibility test was made by disk-diffusion on Mueller Hinton agar and showed greenish colonies, but also it did not exhibit compatible profile with Pseudomonas genus. Therefore, the bacteria presented susceptibility to ampicillin, tetracycline, trimethoprim-sulfa and chloramphenicol (according to criteria of the CLSI [1]), besides cephalosporins, piperacillin/ tazobactam, ticarcillin/clavulate, imipenem, ciprofloxacin, levofloxacin and intermediate susceptibility to aminoglycosides. After confirmed identification of $V$. vulnificus, the therapy was kept with cefepime, ampicillin, ciprofloxacin, and was added doxicycline, due to the gravity of the case. 
Figure 1. Skin lesion in right ankle.

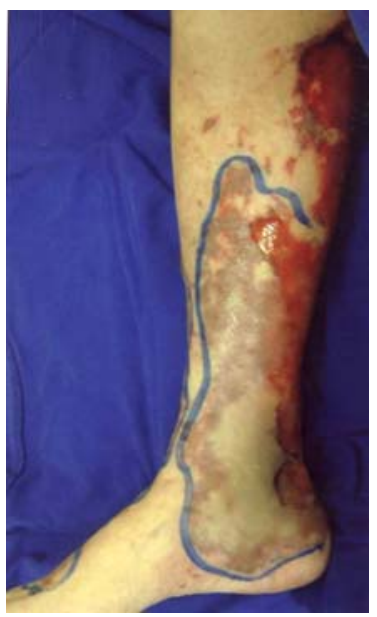

The patient presented transitory improvement, but in the $12^{\text {th }}$ day he presented worsening of symptoms and fungemia by Candida albicans, evolving to death in the $19^{\text {th }}$ day of hospitalization.

\section{Discussion and Literature Review}

Vibrio genus is classified inside Vibrionaceae family. Amongst pathogenic species, $V$. vulnificus is the greatest cause of severe illness. The majority of the infections are related to contaminated food ingestion, as clams and other seafood.

V. vulnificus can be found in coastal sea waters and estuaries in areas of tropical and subtropical climates that possess moderate degree of salinity and temperatures that can vary from 9 to $31^{\circ} \mathrm{C}$, but it is more common where the temperature exceeds $18^{\circ} \mathrm{C}$ [2].

Some littoral regions of the United States of America (U.S.A.) as the coastal regions of Florida, Mexico Gulf, New England and northeast of Pacific are more attacked, as well as areas where the incidence of hepatitis B is high (China and Thailand) [3]. There are also isolated case reports of serious infection in Latin America, as in Uruguay, Chile and Peru [4-6].

In Brazil, there are some reports of isolation of non cholera Vibrio, including $V$. vulnificus, in clams (mainly oysters) and other seafood commercialized in São Paulo and in some points of São Paulo coast, as described for Matté et al. [7,8] and Landgraf et al. [9], in Ubatuba, São Paulo. There are other cases reported by Rodrigues and Hofer [10], in the bay of Sepetiba, Rio de Janeiro; by Barboni [11] in the Bay of Todos os Santos; in Valença, in the state of Bahia; and by Birth et al. [12], in Fortaleza, Ceará

After exposure, the microorganisms reach the bloodstream by skin or intestinal mucosa invasion and multiply itself with production of cytotoxins and enzymes (hemolysins, cytolysins and proteases) that cause extensive cellular damage and are involved in the development of sepsis. The iron is an important growth factor to the bacteria. Therefore, patients who are carrying illnesses like hemochromatosis and hemolytic anemia represent the biggest risk group for development of infection by this agent. It has no predilection for race, gender or age. Other risk groups include carriers of hepatic illnesses as cirrhosis, hepatitis B and C; cancer; HIV; thalassemia; aplastic anemia; liver or kidney transplant; immune suppressive drugs users (chemotherapy, corticosteroids, cyclosporin, tacrolimus); patients on hemodialysis; splenectomized and diabetics [13,14].

The first story of serious illness documented in Brazil took place in the coast of Rio de Janeiro in a diabetic patient who suffered a slight wound in the foot when stepping on in a submerged wooden piece in the sea water while walking on the beach, evolving with cellulitis (being necessary amputation of the right inferior member), sepsis and death after 10 days of evolution. This was described by Joana Brack et al., in the bulletin of the Brazilian Society of Dermatology, in June 2004 [15].

The majority of the patients who develop sepsis are between 50 and 60 years old, being $82 \%$ male. The clinical manifestations more often observed in infections caused by Vibrio are: gastroenteritis: presenting diarrhea (100\%), abdominal pain (89\%), nausea (76\%), vomits (55\%), fever (47\%), occult blood in stool (29\%), headache (24\%) and myalgia (24\%); sepsis: fever ( $>90 \%)$, hypothermia $(<10 \%)$, hypotension (100\%), tachycardia (80-90\%), shock (50-70\%), blisters (80$100 \%)$, acute respiratory failure syndrome $(<5 \%)$ and multiple organ dysfunction (30-50\%); injuries of skin: edema (100\%), pain (100\%), erythema (100\%), blisters (30-50\%), necrosis (30$50 \%)$ and gangrene $(<10 \%)$. These symptoms result from hematogenous dissemination of Vibrio and need extensive debridement, progressing quickly and frequently to death [16]. Laboratory findings include electrolytes altered due to dehydration, severe hypotension and sepsis; occult blood and fecal leukocytes are signals of invasive infectious diarrhea; time of prothrombin and activated partial thromboplastin are raised, and arterial blood gas analysis usually shows severe metabolic acidosis due to tissue hypoperfusion and hypoxia is also observed. Thoracic radiography can show bilateral pulmonary infiltration compatible with acute respiratory discomfort syndrome. Computerized tomography must be requested if the patient evolves with signs and symptoms of compartmental syndrome or necrotizing fasciitis [16-18]. The differential diagnosis includes cholera, gaseous gangrene by Clostridium, disseminated intravascular coagulation, bacterial gastroenteritis and sepsis.

Microbiological diagnosis: currently 12 species of Vibrio are described, the majority having pathogenic potential. They are frequently isolated from blood, wounds of arms and legs, infected eyes and ears, and gallbladder. Rarely, they are reported in patients with meningitis, pneumonia and infection of reproductive organs or urinary tract [2]. There are no evidences of person to person transmission. The Vibrio genus is represented by curved or straight Gram-negative bacilli, measuring 0.5 to $0.8 \mu \mathrm{M}$ in diameter and 1.4 to $2.4 \mu \mathrm{M}$ in length, being facultative anaerobes. The majority of the pathogenic vibrios are mobile and present only 1 polar flagellum. The glucose is fermented by all species, usually 
without gas production. Oxidase is produced, lactose is positive and nitrate is reduced in the majority of the pathogenic species. The phenotypic pattern helps in the differentiation between Vibrio and members of the Enterobactericeae family, Pseudomonas and other non fermenters Gram-negative bacilli. Inoculation in KIA or TSI agar (triple sugar and iron) is useful in the identification of Vibrio phenotypes, since they are glucose and lactose positive. Once identified a microorganism as oxidase positive and fermenter, it is important to make the differentiation between Aeromonas and Plesiomonas genera, which also have the same features. All the Vibrio species grow in nutrient broth or agar when it has the addition of $\mathrm{NaCl} 1 \%$ and it helps in the differentiation of the genera quoted above. Another distinguishing method is the DHA (arginine dehydrogenase), for which Vibrio is negative, whereas Aeromonas and Plesiomonas are positive. It is very important to emphasize that the macroscopic characteristics of the colonies are yellow-greenish and mucoid (better observed on Mueller Hinton agar), they do not grow on MacConkey agar, and it develops abundantly on blood and chocolate agar in 24 hours, in the majority of cases [2,19]. In laboratories with automated microbiology, as for example the Vitek ${ }^{\circledR}$ system, the predictive positive value is of $98 \%$ of trustworthiness in the identification of species of Vibrionaceae family [2].

Although the majority of the species of Vibrio are susceptible to some antibiotics, the therapy does not diminish the time of evolution of the illness. In cases of serious bacillary infections, antibiotic association must be used, seeking synergy and preventing development of resistant bacteria. Quinolone and doxicycline are the chosen therapy. For other infections caused by non cholera Vibrio, that are not gastroenteritis cases, it is indicated a combination of ceftazidime and doxicycline or antipseudomonal penicillins as ticarcillin/clavulanate or piperacillin/tazobactam. Cefotaxime can be an alternative. It is vital to remember that although Vibrio may present as susceptible "in vitro" to aminoglycosides, the use of this antibiotic class is associated with high degree of toxicity. Therefore, they must be avoided [2].

The prophylactic measures to prevent infection by Vibrio are very important in individuals with predisposed conditions to invasive illness already mentioned in this revision. The prophylactic measures are: avoid ingestion of raw or badly-stew seafood; to fry, to cook in steam, to bake or to boil oysters and clams for 4 to 9 minutes or until they are cooked; to boil shrimps or crabs (these can still provoke injuries in case that living creature is manipulated) until the rind becomes pink or the meat is cooked in the middle; fish must be cooked until the thickest part is cloudy; avoid exposition of skin wounds to sea waters in months of summer in regions of the sea coast of the mentioned countries and to look for medical aid quickly if fever, nausea, abdominal pain, diarrhea, myalgia or severe pain in inferior members appear [20].
The prognosis is closely related to the basic clinical condition of the patient, since complications are rare in immunocompetent patients or in gastroenteritis associated to non cholera Vibrio. However, carriers of advanced hepatic illness or other predisposed clinical conditions for infection by this microorganism can evolve with shock and hypotension, compartmental syndrome, multiple organ dysfunction, intravascular coagulation and hemolysis, and acute respiratory discomfort syndromes, besides amputation of members in patients with delay in the debridement. The mortality associated with $V$. vulnificus infection is superior to $50 \%$, and the precocious beginning of the antibiotic therapy, wound debridement and intensive care are important for a better outcome [16,18].

In the event of the patient in question, the worse evolution may have been related to the advanced age associated to antecedents of hepatic steatosis, renal failure and moreover to the gravity generated by the virulence of the microorganism. Combined with these factors, the use of invasive devices in intensive care therapy and extended antibiotic therapy had been indicated as risk factors for serious infections caused by Candida spp.

\section{Conclusion}

Facing any patient recently exposed to marine water or that had manipulated or consumed seafood and presenting infected wounds, conjunctivitis, gastroenteritis or septic shock, the possibility of infection caused by non cholera Vibrio must be thought about. It is important to make yourself familiar with the prophylactic measures, mainly in the predisposed groups.

\section{References}

1. Clinical and Laboratory Standards Institute. Performance Standards for Antimicrobial Susceptibility Testing. Fifteenth Informational Supplement. CLSI / NCCLS document M100-S15. Wayne, PA, USA; 2005.

2. Farmer III J.J., Janda M.J., Birkhead K. Vibrio. In: Murray P.R., Baron E.J., Jorgensen J.H., Pfaller M.A., Yolken R.H. Editors. Manual of clinical microbiology. $8^{\text {a }}$ ed. Washington, D.C: ASM Press; 2003.

3. Morris J.G., Black R.E. Cholera and other vibriosis in the United States. New England Journal of Medicine. 1985;312:343-50.

4. Chicheff Pérez C.A., Bagattini Mari J.C., Gnazo Marengo R.J., et al. Vibrio vulnificus: a lethal summer visitor in Uruguay oceanic water: first national case. Paciente Crítico (Uruguay). 2001; 14:168-74.

5. Poblete U.R., Andresen Hernández M., Pérez Cortés C., et al. Septic shock caused by Vibrio vulnificus: report of 1 case. Revista Médica de Chile 2002;130:787-91.

6. Ibarra J.O., Delgado A., Alvarado D.E. Vibrios nos epidêmicos y Vibrio cholerae 01 asociados a enfermedad diarréica aguda. Evento climatológico “El Niño” - 1998. Hospital Nacional Dos de Mayo. Anales de la Facultad de Medicina (Peru) 1999;60:251-6.

7. Matté G.R. Isolamento de vibrios potencialmente patogênicos em moluscos bivalves. (Tese). São Paulo: Universidade de São Paulo, Faculdade de Saúde Pública; 1993.

8. Matté G.R., Matté M.H., Sato M.I., et al. Potentially pathogenic vibrio associated with mussels from region on the Atlantic coast of Brasil. Journal of Applied Bacteriology 1994;77:281-7. 
9. Landgraf M., Leme K.B.P., Moreno M.L.G. Occurrence of emerging pathogenic Vibrio spp in seafood consumed in São Paulo city, Brazil. Revista de Microbiologia 1996;27:126-30.

10. Rodrigues D.P., Hofer E. Caracterização das espécies do gênero Vibrio do ecossistema água: ostra da baía de Sepetiba, RJ, Brasil. Revista de Microbiologia 1986;17:332-8.

11. Barboni S.A.V. Ocorrência de Vibrio spp. potencialmente patogênicos em moluscos bivalves comestíveis comercializados nos anos 2000 a 2002 nos municípios da área de influência da Baía de Todos os Santos e Valença, Bahia - Brazil. (Tese). São Paulo: Universidade de São Paulo, Faculdade de Saúde Pública; 2003. p171.

12. Nascimento S.M.M., Vieira R.H.S.F., Theophilo G.N.D., et al. Vibrio vulnificus as a heath hazard for shrimp consumers. Revista do Instituto de Medicina Tropical de São Paulo 2001;43:263-6.

13. Hor L.I., Chang T.T., Wang S.T. Survival of Vibrio vulnificus in whole blood from patients with chronic liver diseases: association with phagocytosis by neutrophils and serum ferritin levels. Journal of Infectious Diseases 1999;179:275-8.
14. Brennt C.E., Wright A.C., Dutta S.K. Growth of Vibrio vulnificus in serum from alcoholics: association with high transferin iron saturation. Journal of Infectious Diseases 1991;164:1030-2.

15. Brack J., Martinez A., Lugarinho M., et al. Infecção cutânea por Vibrio vulnificus. Boletim da Sociedade Brasileira de Dermatologia (Rio de Janeiro) 2004;abr/mai/jun:6.

16. Klonts K.C., Lieb S., Schreiber M. Syndromes of Vibrio vulnificus infections. Clinical and Epidemiologic features in Florida cases, 1981-1987. Annals of Internal Medicine 1988;109:318-23.

17. Howard R.J., Lieb S. Soft tissue infections caused by halophilic marine vibrios. Archives of Surgery 1988;123:245-9.

18. Ulusarac O., Carter E. Varied clinical presentations of Vibrio vulnificus infections: a Report of Four Unusual Cases and Review of the Literature. Southern Medical Journal 2004;97:163-8.

19. Koneman E.W., Allen S.D., Janda W.M., et al. Editores. Diagnóstico microbiológico. $5^{\text {a }}$ ed. Rio de Janeiro: MEDSI; 2001. cap.6, p.346-59.

20. Mouzin E., Mascola L., Tormey M.P. Prevention of Vibrio vulnificus infections: assessment of regulatory educational strategies. JAMA 1997;278:576-8. 